\title{
ИНТЕЛЛЕКТУАЛЬНАЯ ИСТОРИЯ
}

Ягодкин А.А.

DOI: 10.7256/2222-1972.2016.2.17617

При иитировании этой статьи сноска на доі обязательна

\section{Человек 1898 года: Интеллектуальная биография Рамиро де Маэсту}

\begin{abstract}
Аннотачия. Предметом исследования в представленной работе является биография и творческое наследние испанского интеллектуала писателя и философа Рамиро де Маэсту, а обвектом исследования - эволючия его взглядов, которая заключалась в постепенном переходе от либеральных идей “Поколения 1898» к консервативным позичиям. Автор последовательно рассматривает и анализирует этапы биографии и творческого пути Рамиро де Маэсту, уделяя особое внимание историческому контексту, влиянию интеллектуальной среды и соииокультурным факторам, определивиим идейную эволюиию писателя. Основным методом исследования является метод новой интеллектуальной биографии, автор опирается на методологические разработки иентра интеллектуальной истории ИВИ РАН по "новой интеллектуальной истории", "персональной истории" и "биографическому исследованию". В результате исследования автор приходит к следуюшим выводам: эволюиия взглядов Рамиро де Маэсту была обусловлена сочиокультурной и интеллектуальной средой, а также историческим контекстом эпохи. Отправной точкой для эволючии взглядов стали трагические события 1898 года, через переосмысление которых де Маэсту постепенно приходит к разработке кониепиии Испанидад. Новизна исследования определяется недостаточной известностью фигуры Рамиро де Маэсту в российском научном дискурсе, а также первым опытом исследования его жизни и творчества с позииий "новой интеллектуальной биографии".
\end{abstract}

Ключевые слова: Рамиро де Маэсту-и-Уитни, биография, интеллектуальная история, наииональная идея, история Испании, консерватизм, начало ХХ века, политическая публицистика, Латинская Америка, наииональная идентичность.

Abstract. The research subject of the presented work is the biography and creative legacy of the Spanish intellectual, writer and philosopher Ramiro de Maeztu, while the research object is the evolution of his views, gradually going from the liberal ideas of the Generation of '98 to his later conservative views. The author examines and analyses the stages in the biography and literary career of Ramiro de Maeztu, paying special attention to the historical context, the influence of his surrounding intellectual environment, and the sociocultural factors that determined the ideological evolution of the writer. The key method of research applied in this study is the method of the "new intellectual biography". The author relies on the methodological developments carried out by the Centre for Intellectual History (Russian Academy of Sciences) on Modern Intellectual History, Personal History, and biographic research. As a result of this research the author comes to the following conclusions: the evolution of Ramiro de Maeztu's views was caused by the sociocultural and intellectual environment of the time, as well as the historical context of the era. The tragic events of 1898 became the starting point for the evolution of de Maeztu's views, which led to the development of his concept of "Hispanidad". The novelty of this research lies in the fact that Ramiro de Maeztu is not a well-known figure in Russian historiography. This study is the first attempt to explore Ramiro de Maeztu's life through the approach of "the new intellectual biography".

Key words: Ramiro de Maeztu y Whitney, biography, intellectual history, national idea, history of Spain, conservatism, beginning of the 20th century, political publicism, Latin America, national identity.

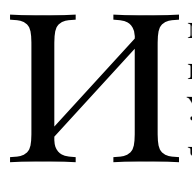
мя испанского писателя, философа и публициста Рамиро де Маэсту-иУитни малоизвестно российскому читателю. В историю он вошел как один из представителей «поколения 1898 года»плеяды интеллектуалов, сделавших главной темой своего творчества размышление о причинах нарастающего социально-политического и духовного кризиса Испании, возможных путях его преодоления, ответственности патриотов за судьбу Родины. К концу жизни Рамиро де Маэсту уже являлся ярким сторонником правоконсервативных идей, защитником традиционных ценностей, идеологом и главным разработчиком концепции «Испанидад», одним из предтечей идеологии франкизма. Зигзаги этой бурной интеллектуальной биографии емко отразили специфику одной из самых драматических эпох в истории Европы, разграничившей Новое и Новейшее время. Для Испании, некогда великой 
колониальной державы, оказавшейся на периферии европейского экономического и политического пространства, эти годы стали временем сложнейшего исторического выбора.

Начало творческого пути Р. де Маэсту пришлось на конец XIX века, когда кризисная ситуация в испанском обществе стала приобретать черты «национальной катастрофы». «Точкой кипения» для испанцев прослужили события 1898 года, когда бурбонская монархия потерпела сокрушительное поражение в войне с США. Результатом стала потеря Испанией последних латиноамериканских колоний - Кубы, Филиппин и Коста-Рики, что нанесло удар не только по экономическим и геополитическим позициям страны, но заставило окончательно расстаться с призраком испанского колониального величия. Почти сакраментальный вопрос «Что дальше?» вызвал очень смешанные настроения в испанском обществе. Как справедливо отмечает Севильяно Калеро, «актуальность событий, связанных с утратой колоний в 1898 г., в испанской культуре были объединены с вопросом национальной идентичности» [1] . Испанская интеллектуальная элита была увлечена идеями исторического обновления страны, но обостренно рефлексировала по поводу «катастрофы 1898 года». Эта причудливая смесь эйфории и пессимизма создавала совершенно необычную духовную атмосферу в обществе, ломала привычные каноны политического мышления и духовного творчества [2].

При самом обзорном взгляде на историю Испании XIX века можно выявить противостояние двух противоположных тенденций в общественно-политической жизни этой страны - либеральной, явившейся порождением французской революции, и консервативной, сопряженной с сохранением традиционных сословных и конфессиональных ценностей. После «событий 1898 года» противостояние представителей этих двух направлений приобрело особенно ожесточенный характер. Обостренная рефлексия интеллектуалов породила так называемый «миф 1898» (el mito de novente у ocho), который ввел в испанскую духовную традицию ощущение национальной катастрофы, сформировал картину бедствия, преодоление которого потребует сосредоточения всех сил нации, проявления ее истинных сил и ценностей. Большинство представителей «поколения 1898 года» находилось скорее на либеральных позициях : для него «проблема Испании» заключалась в поисках путей превращения испанского общества в современ- ное, динамичное, открытое новейшим тенденциям европейской жизни. Но «соавторами» «мифа 1898» выступали и интеллектуалы, продолжавшие в своем творчестве многовековую консервативную традицию. Наиболее ярко в этот период зазвучал голос М. Менендеса-и-Пелайо, философа, историка культуры и литературоведа. В своих трудах он представил концепцию испанской национальной культуры, опирающейся на традиционные католические ценности [3, с. 45]. Эти идеи окажут впоследствии огромное влияние на духовную эволюцию Рамиро де Маэсту. Себя он называл «человеком 1898», подчеркивая, что именно драматические события конца 1890-х гг. дали толчок его идейной эволюции. Но со временем де Маэсту все более скептически относился к «поколению 1898», доказывая, что проблемы испанского общества лежат гораздо глубже, нежели демонстрирует дискуссия о потере колоний или формирование актуальной политической программы. «Что является тем, что претендующие быть учеными называют “Поколением 1898 г.”? Почему они не говорят о поколении 1900 или 1891 года?», - писал он [4 с. 65]. Для де Маэсту «миф 1898» являлся скорее поводом для размышлений о глубинных причинах тех метаморфоз, которые происходили с испанским обществом, а также для поиска ответа на один из ключевых вопросов не только испанской, но и европейской интеллектуальной традиции - какова взаимосвязь истории и современности, прогресса и традиции, духовности и социального динамизма.

Рамиро де Маэсту-и-Уитни родился в 1875 г. в Витории, в стране басков. В будущем борце за испанскую идентичность соединилась кубинская, баскская и английская кровь. Его отец был баском, но имел кубинские корни и владел плантациями в этой тогда еще испанской колонии. Мать Рамиро, Хуана Уитни , была дочерью английского посла в Париже, где и познакомились родители будущего писателя. Все эти три страны сыграли немалую роль в судьбе де Маэсту. В детстве и отрочестве он побывал и на Кубе, и во французской столице, несколько лет прожил в Лондоне. Самые счастливые годы в детстве де Маэсту были связано с его пребыванием на Кубе, с жизнью на отцовских плантациях. Этот факт впоследствии оказал большое влияние на мировоззрение юного де Маэсту, для семьи которого потеря Кубы стала не только прощанием с привычным укладом жизни, но и причиной разорения. Описывая детские годы де Маэсту, Альберто Санчес емко отмечает: «Роскошь сменилась 


\section{Исторический журнал: научные исследования № 2 (32) • 2016}

DOI: $10.7256 / 2222-1972.2016 .2 .17617$

посредственностью, посредственность бедностью, бедность нищетой» [5, с.12]

Спасаясь от невзгод, молодой де Маэсту отправляется во Францию, где пробует себя в роли коммерсанта. В Париже он пробыл всего несколько месяцев, но за это время успел прочувствовать и дух вольнодумства, характерный для столицы этой «просвещенной страны», и всю жесткость капиталистических реалий новой эпохи. Он понял свою полную несостоятельность в качестве торговца и промышленника, но, что еще важнее, остро прочувствовал разительное несоответствие испанской и французской общественной жизни. К нему пришло осознание нарастающей отсталости его родины, и именно это ощущение станет лейтмотивом раннего творчества, определит его причастность к «поколению 1898», пребывание в лагере сторонников европеизации Испании. Однако память его сохранит и воспоминания о счастливых годах, проведенных на Кубе, о притягательности аристократического образа жизни, о ценностях, «которые он впитал с раннего детства и которые останутся где-то глубоко в его сердце, в какой-то момент отойдя на второй план». [6]

На путь «борца, вооруженного пером», как его называет А. Санчес [5, с. 5], де Маэсту встал сразу по возвращении из Франции, поселившись в баскской столице Бильбао. Именно здесь в возрасте 20 лет де Маэсту публикует свою первую статью. В 1897 г. он переехал в Мадрид, где вскоре примыкает к либеральному крылу «Поколения 1989». События 1898 года отозвались в душе юного де Маэсту осознанием национального краха и стремлением к патриотическому действию. В столице он сталкивается с различными настроениями, слышит голоса интеллектуалов, не способных и не желающих понять друг друга. Под влиянием этих впечатлений де Маэсту начинает поиск пути «к другой Испании». Именно так называется его первая и главная книга, на основании которой можно судить о взглядах де Маэсту в период «Поколения 1898». [7]

Первая книга де Маэсту, по его собственному признанию, - это не программа преобразования Испании, а лишь критическое осмысление драматической ситуации, в которой оказалось испанское общество. На ее страницах нет развернутых программных рассуждений, но рефреном звучит призыв к национальному возрождению, решительному изменения всех сторон жизни испанского общества при сохранении его уникального исторического опыта и мощной жизненной силы. «Мы сыты по горло монотонным чтением калек, которое вечно слышим, когда идем по улице. Хватит! Хватит морали калек! В каждом народе рождается собственная мораль силы!»- восклицал де Маэсту. Но несмотря на столь ярко выраженный пафос де Маэсту не переступал грань радикализма. Он язвительно писал о таких революционерах, как Накенс [Хосе Накенс Перес-испанский публицист, активист республиканского и антиклерикального движения - A.Я.], которые «не видят пути к улучшению, пока не будет потоплен последний карлист и священник, традиционалисты же мечтают уничтожить протестантов, либералов и массонов». [7 с. 240]. Сам де Маэсту принадлежал к немногочисленному умеренному крылу интеллектуалов из «поколения 1898». Эта позиция стала особенно очевидной после создания «группы трех», куда помимо де Маэсту вошли П. Бароха и Асорин (Хосе Мартинес Руис). По своим воззрениям участники «группы трех» были близки к известному историку права и политику Хоакину Косте-и-Мартинесу, автору прогрессисткой программы «Возрождения и европеизация Испании».

Негативное отношение к радикализму в любых его проявлениях было во многом порождено не только негативными впечатлениями де Маэсту от жесткого противостояния консервативного и либерально-прогрессистского течений испанской общественно-политической мысли, но и его собственным жизненным опытом. Острые переживаниями молодого аристократа, испытавшего тяготы разорения, разочарование нереализованных амбиций, растерянность от стремительной ломки понятного и привычного мира повлияли на его мировоззрение. Увлечение прогрессистскими идеями не стало для де Маэсту препятствием в дальнейшей духовной эволюции. Сохранив приверженность мечте «поколения 1898» о национальном возрождении Испании, он со временем все большее внимание уделял осмыслению той мировоззренческой, культурной и социальной основы, на которой это возрождение возможно. Для периода «духовных поисков», начавшегося после распада «Поколения», очень характерна статья де Маэсту «Уменьшенная молодость». В ней автор представляет от третьего лица не только собственный литературный портрет, но и свое жизненное кредо: «Есть в Испании писатель, которого появилась устойчивая идея подобно поплавку посвятить себя ветру и морю, и явиться источником активности, который ориентирован на то, чтобы сделать перо ин- 
струментом достижения әффективности. Этого писателя зовут Рамиро де Маэсту» [8, с. 108]. Избрав путь интеллектуального поиска, де Маэсту сознательно отказался позиционировать себя в том или ином политическом лагере. Это позволило ему органично принять идеи совершенно разнонаправленных течений общественной мысли, предпочтя в итоге консервативный католицизм как осмысленную, жизненную позицию, а не политическую программу.

Самобытность де Маэсту в качестве испанского консервативного мыслителя во многом объясняется и долгим проживанием его за границей, в частности в Англии. Проживая с 1910 по 1919 год в Лондоне, де Маэсту получил возможность критического осмысления европейской либеральной традиции, равно как и перспектив европейского консерватизма. Это время было связано для де Маэсту с активной перепиской с «испанским европейцем» Х. Ортега-и-Гассетом и увлечением гильдейским социализмом. Социалистические мотивы в творчестве де Маэсту, как замечают некоторые исследователи, можно заметить еще в книге «К другой Испании», хотя их преломление в сознании де Маэсту оказалось весьма специфичным [9]. Свои первые рассуждения о перспективах «третьего пути» де Маэсту изложил в небольшой статье, изданной в журнале «Новая Эра». Однако на дальнейшее развитие его взглядов решающее значение оказала мировая война. Оказавшись в Англии в момент начала мировой катастрофы, де Маэсту смог ощутить экономические, политические и психологические аспекты общественного кризиса, разражавшегося в европейском обществе. Уже в 1916 г. он пишет книгу «Власть и общество через призму войны», которую позже перепишет по-испански и по возвращении на родину в 1919 г. издаст ее под названием «Кризис гуманизма». Для анализа автор данной публикации использовал испанскую версию работы, переизданную в 1951 г. [10]

Значимость книги «Кризис гуманизма» в интеллектуальной биографии де Маэсту определяется двумя обстоятельствами. Во-первых, в этой работе автор впервые представил свою концепцию авторитарного государства, предлагая новый путь развития в условиях острого кризиса современного общества. Рассуждая о «естественно-иерархической» структуре общества и власти, он доказывает необходимость жесткой консолидации власти (unidad de poder). Вовторых, в «Кризисе гуманизма» де Маэсту впервые выступает с позиций религиозного мысли- теля, считая главными «бедами» европейской истории протестантизм и Реформацию, а также явно идеализируя средневековую католическую традицию. Эта установка резко усилила присущие творчеству де Маэсту консервативные нотки, и превратила его в ярого апологета концепции «порядка» (или концепции «защиты»), столько популярной среди интеллектуалов правого толка в первой трети XX века.

Следующий значимый этап в биографии Рамиро де Маэсту условно можно назвать «аргентинским». В Аргентину он оправился в 1923 г. в качестве посла диктаторского режима генерала М. Примо де Риверы. За четырехлетний период между возвращением из Лондона и началом дипломатической миссии в бывшей колонии де Маэсту прочно вошел в среду испанских интеллектуалов из «правового» лагеря, разделив их неприязнь к любому революционному движению, мечты о возрождении «национального духа». В своих трудах он нередко обращался и к идеям консерваторов-традиционалистов М. Менендесаи-Пелайо и Х. Доносо Кортеса, доказывавшим особый характер исторического пути Испании и уникальную роль испанской религиозности. Эти идеи во многом и стали фундаментом для концепции «Испанидад», разработанной де Маэсту [11]. Но сам термин «Испанидад» де Маәсту услышал уже в Аргентине. Считается, что в научный оборот его ввел Сакариас де Вискарра, священник, эмигрант, личный друг Р. де Маэсту. Сам Вискарра, однако, указывал, что не является автором термина и прослеживает историю его употребления вплоть до I века н. э. [12]

Отправившись в Аргентину, Р. де Маэсту оказался в среде интеллектуалов, духовно и генетически связанных с испанским прошлым аргентинских клерикалов и креольской аристократии, сохранивших еще отголоски имперских идей. Особой популярностью в этой среде пользовалась националистическая концепция «архентинидад», согласно которой истинными аргентинцами могут считаться лишь потомки испанских эмигрантов и завоевателей, наследники имперского прошлого бывшей метрополии $[13$, с. 218]. Однозначно оценить влияние этих идей на де Маэсту сложно, однако аргентинский период сыграл важную роль в укреплении его консервативного кредо и внес весомый вклад в формирование доктрины «Испанидад».

Вернувшись в Испанию после падения режима М. Примо де Риверы, де Маэсту стал свидетелем революции 1931 г., то есть событий, оце- 


\section{Исторический журнал: научные исследования № 2 (32) • 2016}

DOI: $10.7256 / 2222-1972.2016 .2 .17617$

нить которые иначе, чем национальную катастрофу, он не мог. Де Маэсту становится одним из лидеров консервативной организации «Испанское действие» и редактором одноименного журнала, издававшегося в 1931-1936 гг. На страницах журнала регулярно появлялись и статьи самого де Маэсту, в которых он проявляет себя как непримиримый борец за испанскую идентичность, незыблемость традиционных ценностей и верность историческому пути Испании. В этих публикациях Маэсту впервые представил основные идеи своей концепции «Испанидад». Позднее они были обобщены в книге «Защита Испанидад», изданной в 1934 г. [14]. Введением к книге стала программная статья «Испанское действие», вышедшая еще в первом номере журнал в 1931 г. [15], а первые три главы были сформированы из материалов статьи «Испанидад» [16], опубликованной в том же номере.

Испанидад, имеющий у Вискарры религиозный и географический смысл, на страницах книги де Маэсту становится философской категорией, вбирающей в себя основные элементы испанской консервативной триады «Dios, Patira, Rey» (Бог, Родина, Король). Для де Маэсту «Испанидад» - это некий идеал великого служения, восходящий к средневековому испанскому рыцарству и основанный на идеалах христианской веры XVI века [14]. Именно этот идеал, сформированный Испанской империей раннего нового времени, он считает основой испанского и величия Испании. Де Маэсту также рассуждал об общности путей развития Испании и Латинской Америки и о причинах «рассеивания духа», которые сводил к распространению «инородных» либеральных идей, пришедших с пораженной бичами революции и протестантизма Европы. Не случайно, и программная статья де Маэсту, и его книга «Защита Испанидад», начинается с яркого образа, выражающего двойственность испанской интеллектуальной традиции: «Испания есть дуб, овитый плющем». Дуб - это традиционные испанские ценности, католицизм, монархия и испанский дух, идеал служения, кихотизм, а плющ - приходящие, не укоренившиеся западные ценности.

В контексте идей «Защиты Испанидад» совершенно иначе воспринимались и проблемы, поднятые «поколением 1898». Национальный кризис того времени де Маэсту рассматривал уже как следствие не просто потери колоний, а именно как «рассеивание Испанидад», утрату национальной идентичности. Воспринимая концепцию Испанидад как идеал рыцарского служения, де Маэсту рассматривает Испанию и Латинскую Америку, потерявших этот идеал, как народы, которым не во что больше верить. «Испанец верит либо в абсолютные ценности, либо не верит не во что вовсе» [17]. В этих условиях концепт «защиты» становится для де Маэсту не только основной его жизненной позиции, но и символом выбора любого испанца. Он выражает эту мысль это в емкой формуле: "Ser es defenderse” («Существовать, значит защищаться») [14]. Такое понимание защиты как единственно возможного способа существования сближает Рамиро де Маэсту с экзистенциализмом, открывая в его позднем творчестве глубокий философский подтекст. Де Маэсту перекладывает эти идеи на политическую почву, в духе консервативной традиции он трактует «защиту» как контрреволюцию, являющуюся единственным способом выжить и сохранить свою идентичность.

Завершая рассмотрение основных этапов биографии и творчества Рамиро де Маэсту, ещё раз остановимся на основных факторах, определивших его идейную эволюцию. Безусловно, огромное влияние на де Маэсту оказали интеллектуальная среда и исторический контекст. Всё творчество де Маэсту было посвящено поиску глубинных причин кризиса, в котором оказалась Испания на рубеже веков и путей его преодоления. На протяжении всей своей жизни он знакомится с различными интеллектуальными традициями, существующими как в испанской интеллектуальной среде, так и за её пределами, общается с интеллектуалами различных политических взглядов и национальностей, критически переосмысливает все идеи, с которыми он сталкивается, продолжая следовать своей цели. Важность влияния среды и эпохи на творчество де Маэсту и его идейную эволюцию стоит учитывать ещё и в том смысле, что именно среда сформировала характер де Маэсту.

Говоря об интеллектуальной биографии де Маэсту, нельзя не учитывать те факторы, которые повлияли на формирование его характера: это и аристократическое происхождение, и беззаботное детство на Кубе, и впечатление от капиталистической Франции. Однако главным событием, определившим путь Рамиро де Маэсту, стало поражение Испании в испано-американской войне 1898 года, до конца жизни воспринимающееся им как трагедия. Именно под влиянием событий 1898 года де Маэсту встает на путь поиска причин кризиса, послужило окончательному краху привычной ему картины мира, именно поэтому отход де Маэсту на консервативные позиции является 


\section{Интеллектуальная история}

DOI: $10.7256 / 2222-1972.2016 .2 .17617$

не случайным «переворотом» в его взглядах, спровоцированным первой мировой войной, а вполне закономерным итогом его творчества. «Лондонский» и «аргентинский» этапы его творчества, обратившие его к анализу состояния современно- го общества и к традициям испанской империи, были во многом подготовлены установками, заложенными в де Маэсту после событий 1898 года. Исходя из этого, мы можем согласиться с самим писателем, назвавшим себя «человеком 1898 года».

\section{Библиография:}

1. Calero S. El mito de 98 en la cultura española [Электронный ресурс] URL : http://dialnet.unirioja.es/servlet/ articulo?codigo=1166024 ( дата обращения 30.05.2015).

2. Jose Flores M. Ramiro de Maeztu y la crisis del fin del siglo [Электронный ресурс] URL: http://cvc.cervantes.es/literatura/ aispi/pdf/11/11_303.pdf ( дата обращения 30.05.2015).

3. Пономарева Л. В. Испанский католицизм XX века. М.: Наука, 1989 - 288 с., с ил.

4. Maeztu R. de. El poder de la mentura y la generacion del 98 // Maeztu R. de. Autobiografia. Madrid.: Editora national, 1962. P. 64 - 68.

5. Sanchez A. Introduccion // Maeztu R. de. Don Quijote o el Amor. Salamanca: Editores Anaya, 1964,-P. 5 - 45.

6. Cerrato C. El joven Maeztu y la canalla periodista [Электронный ресурс] URL:https://pendientedemigracion.ucm.es/info/ especulo/numero37/maeztu.html ( дата обращения 9.06.2015).

7. Maeztu R. de. Hacia otra España. Madrid: Rialp, 1967 - 267 p.

8. Maeztu R. de. Juventud menguante. Autobiografías [Электронный ресурс] URL: http://www.filosofia.org/hem/190/alm/ ae1214.htm ( дата обращения 13.06. 2015).

9. Кулешова В. В. Проблема Испании в полемической публицистике Рамиро де Маэсту 1896-1936 годов // Проблемы испанской истории. М, 1979 - С. $106-134$.

10. Maeztu, R. de La Crisis del Humanismo Buenos Aires: Ed. Sudamericana, 1951. - 457 p.

11. Пономарева Л. В. Хуан Доносо Кортес// Проблемы испанской истории, 1979. С. 135 - 170.

12. Vizcarra, Z de Origen del nombre, concepto e fiesta de la Hispanidad. [Электронный ресурc] URL:http://www.filosofia.org/ hem/194/esp/9441007a.htm (дата обращения 20.06.2015)

13. Шульговский А.Ф. Национализм в Латинской Америке. М.: «Наука», 1976. - 238 c.

14. Maeztu R. de . Defensa de la Hispanidad [Электронный ресурс] URL: http://hispanidad.tripod.com/maezt.htm (дата обращения 5.05.2015)

15. Maeztu, R. de. - Accion Española [Электронный ресурс] // URL: http://www.filosofia.org/hem/193/acc/e01001.html ( дата обращения 1.02. 2014)

16. Maeztu, R. de. La Hispanidad.// Accion Española - 1931.-№ 1 - p.8-16 [Электронный pecypc] // URL: http: // www.filosofia. org/hem/193/acc/e01008.html (дата обращения 17.07.2013).

17. Тулаев П. Стрелы Фаланги [Электронный ресурс] URL: http://www.sensusnovus.ru/analytics/2013/10/19/17325.html (дата обращения: 22. 03.2014)

\section{References (transliterated):}

1. Calero S. El mito de 98 en la cultura española [Elektronnyi resurs] URL : http://dialnet.unirioja.es/servlet/ articulo?codigo=1166024 ( data obrashcheniya 30.05.2015).

2. Jose Flores M. Ramiro de Maeztu y la crisis del fin del siglo [Elektronnyi resurs] URL: http://cvc.cervantes.es/literatura/aispi/ pdf/11/11_303.pdf ( data obrashcheniya 30.05.2015).

3. Ponomareva L. V. Ispanskii katolitsizm XX veka. M.: Nauka, $1989-288$ s., s il.

4. Maeztu R. de. El poder de la mentura y la generacion del 98 // Maeztu R. de. Autobiografia. Madrid.: Editora national, 1962. P. 64 - 68.

5. Sanchez A. Introduccion // Maeztu R. de. Don Quijote o el Amor. Salamanca: Editores Anaya, 1964,-P. 5 - 45.

6. Cerrato C. El joven Maeztu y la canalla periodista [Elektronnyi resurs] URL:https://pendientedemigracion.ucm.es/info/ especulo/numero37/maeztu.html (data obrashcheniya 9.06.2015).

7. Maeztu R. de. Hacia otra España. Madrid: Rialp, 1967 - 267 p.

8. Maeztu R. de. Juventud menguante. Autobiografías [Elektronnyi resurs] URL: http://www.filosofia.org/hem/190/alm/ae1214. htm ( data obrashcheniya 13. 06. 2015).

9. Kuleshova V. V. Problema Ispanii v polemicheskoi publitsistike Ramiro de Maestu 1896-1936 godov // Problemy ispanskoi istorii. M, 1979 - C. $106-134$.

10. Maeztu, R. de La Crisis del Humanismo Buenos Aires: Ed. Sudamericana, 1951. - 457 p.

11. Ponomareva L. V. Khuan Donoso Kortes// Problemy ispanskoi istorii, 1979. S. 135 - 170.

12. Vizcarra, Z de Origen del nombre, concepto e fiesta de la Hispanidad. [Elektronnyi resurs] URL:http://www.filosofia.org/ hem/194/esp/9441007a.htm (data obrashcheniya 20.06.2015)

13. Shul'govskii A.F. Natsionalizm v Latinskoi Amerike. M.: «Nauka», 1976. - 238 c.

14. Maeztu R. de . Defensa de la Hispanidad [Elektronnyi resurs] URL: http://hispanidad.tripod.com/maezt.htm (data obrashcheniya 5.05.2015)

15. Maeztu, R. de. - Accion Española [Elektronnyi resurs] // URL: http://www.filosofia.org/hem/193/acc/e01001.html ( data obrashcheniya 1.02.2014)

16. Maeztu, R. de. La Hispanidad.// Accion Española - 1931.-№ 1 - r.8-16 [Elektronnyi resurs] // URL: http: // www.filosofia.org/ hem/193/acc/e01008.html (data obrashcheniya 17.07.2013).

17. Tulaev P. Strely Falangi [Elektronnyi resurs] URL: http://www.sensusnovus.ru/analytics/2013/10/19/17325.html (data obrashcheniya: 22. 03.2014) 